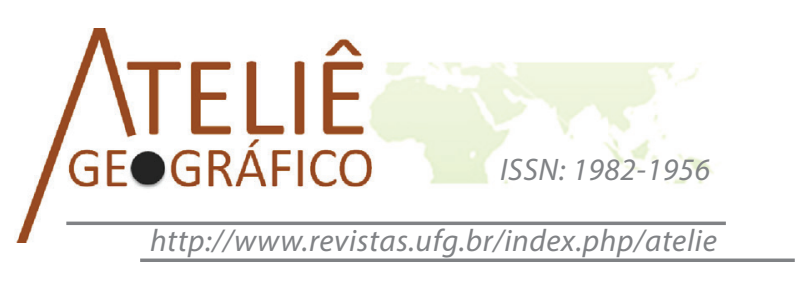

\title{
O estudo de cidade e a formação do professor de geografia: contribuições para o desenvolvimento teórico-conceitual sobre cidade e vida urbana
}

\author{
El estúdio de la ciudad y la formacion del profesor de \\ geografia: contribuciones para el desarrollo \\ teórico-conceptual sobre ciudad y vida urbana
}

\section{The city study and the training of the geography teacher: contributions to the theoretical-conceptual development of city and urban life}

\author{
Lana de Souza Cavalcanti \\ Universidade Federal de Goiás \\ 1s.cavalcanti@uol.com.br
}

\begin{abstract}
Resumo
A investigação que sustenta este texto tem como tema "Geografia e Ensino de Cidade", visando à compreensão do espaço urbano, das práticas cotidianas e dos modos de abordar esses temas no ensino. Seu objetivo geral é analisar potencialidades da mediação didática para desenvolver o pensamento teórico-conceitual sobre cidade e vida urbana em experiências de alunos do estágio curricular (momento formativo relevante) do curso de Geografia da Universidade Federal de Goiás. A abordagem metodológica adotada é a da investigação qualitativa, na modalidade de pesquisa-ação, com seus procedimentos pertinentes. No texto são tratados os dados referentes à pesquisa bibliográfica e a entrevistas com especialistas na área, a partir de algumas questões: quais os conceitos geográficos mais importantes para compreender as cidades latino-americanas no contexto contemporâneo? Como eles podem ser sistematizados em uma rede de significados para seu ensino?. Os resultados, até o momento, correspondem a uma sistematização das contribuições da produção em Geografia urbana para o ensino e ao levantamento de conceitos para subsidiar sua abordagem.
\end{abstract}

Palavras-Chave: mediação; ensino de Geografia; ensino de cidade; formação de professores 


\begin{abstract}
Resumen
La investigación que sustén este texto tiene como tema "Geografía y Enseñanza de la ciudad”, visando a la comprensión del espacio urbano, de las prácticas cotidianas y de los modos de abordar esos temas em la enseñanza. Su objetivo general es analizar potencialidades de la mediación didáctica para desarrollar el pensamiento teórico-conceptual sobre ciudad y vida urbana en experiências de alumnos del estágio curricular (momento formativo relevante) de la carrera de Geografía de la Universidade Federal de Goiás. El abordaje metodológica adotada es la de la investigación calitativa, del tipo investigación-acción, com sus procedimentos pertinentes. Em el texto son tratados los datos referentes a la investigación bibliográfica y las citas com especialistas en el área, a partir de algunas cuestiones: quales son los conceptos geográficos $\mathrm{m}$ ás i mportantes $\mathrm{p}$ ara $\mathrm{c}$ omprender las ciudades latino-americanas en el contexto contemporâneo? Como eles pueden ser sistematizados en uma red de significados para su enseñanza? Los resultados, hasta el momento, corresponden a una sistematización de las contribuciones de la producción em Geografía urbana para la enseñanza y al levantamento de conceptos para subsidiar su abordaje.
\end{abstract}

Palabras Clave: mediación; enseñanza de la Geografía; enseñanza de la ciudad; formación de profesores

\begin{abstract}
The research that supports this text has the theme "Geography and City Teaching", aiming at the understanding of the urban space, the daily practices and the ways of approaching these themes in teaching. Its general objective is to analyze the potential of didactic mediation to develop theoretical-conceptual thinking about city and urban life in the experiences of students of the curricular stage (relevant formative moment) of the Geography course of the Federal University of Goiás. Qualitative research, in the research-action modality, with its pertinent procedures. In the text the data on bibliographic research and interviews with experts in the area are treated, based on some questions: what are the most important geographical concepts to understand Latin American cities in the contemporary context? How can they be systematized into a network of meanings for their teaching? The results, to date, correspond to a systematization of the contributions of production in urban geography for teaching and raising concepts to subsidize their approach.

Keywords: Mediation; Teaching of Geography; Teaching of the city; Teacher training
\end{abstract}

\title{
Primeiras palavras
}

Esse texto apresenta resultados parciais de pesquisa realizada que dá continuidade à investigação anterior intitulada Jovens escolares e a vida urbana cotidiana: um eixo na formação de professores de Geografia, que objetivou analisar a potência do estudo de temáticas da Geografia Urbana na formação inicial e continuada de professores de Geografia voltada para a prática cidadã. Em razão dessa investigação foi possível sistematizar leituras e estudos sobre a produção da Geografia urbana brasileira; conhecer percepções de jovens em formação profissional em Geografia sobre as temáticas da pesquisa; aprofundar estudos sobre juventude e práticas espaciais cotidianas. $\mathrm{O}$ tema 
mais geral dessa linha de investigação é "Geografia e Ensino de cidade”, considerando as demandas de ampliar a compreensão dos alunos sobre sua vida cotidiana, seus lugares e suas práticas espaciais em diferentes lugares. A presente pesquisa, a ser desenvolvida no período de 2016 a 2019, volta-se para compreender melhor o espaço urbano e as práticas cotidianas e os modos de abordar a Geografia urbana, pela mediação didática, tendo como eixo a formação de alunos estagiários de Curso de Geografia. Baseando-se em indicações de que o ensino de cidade ganha relevância quando associado à formação para a cidadania, o que requer formação profissional específica, o objetivo geral da pesquisa é: analisar as potencialidades da mediação didática para o desenvolvimento do pensamento teóricoconceitual sobre cidade e vida urbana em experiências formativas de alunos estagiários do curso de Geografia da UFG. Para desenvolver a investigação, adotou-se a perspectiva qualitativa e a modalidade de pesquisa-ação. Os procedimentos metodológicos definidos são: levantamento e análise bibliográfica; análise documental do Projeto Pedagógico do Curso (PPC) e de planos de ensino; questionários com especialistas na área; grupos de discussão; Projetos de Intervenção Pedagógica; Avaliação da experiência de alunos estagiários. Como resultado dessa investigação, espera-se ampliar a compreensão das demandas da formação de professores de Geografia, com vistas a desenvolver um trabalho com autoria intelectual, que possa contribuir para a prática urbana cidadã dos seus alunos.

O propósito de ampliar os estudos nessa temática "Ensino de cidade" está relacionado à necessidade de aprofundar conhecimentos teóricos e práticos sobre as demandas da formação do professor para enfrentar o permanente desafio de dar significado efetivo ao ensino de Geografia. Nessa trajetória de investigação, inicialmente preocupei-me com o delineamento de argumentos que explicavam e defendiam a relevância do ensino de cidade, no âmbito da Geografia escolar voltada à formação para a vida cotidiana, em especial de jovens escolares. Com essa meta, meu interesse volta-se agora para os modos como os jovens alunos universitários formam, no Curso de Geografia, o pensamento teórico-conceitual sobre cidade e vida urbana e para o papel que pode desempenhar o Estágio nesse processo, propiciando experiências docentes com mediação didática.

\section{A problemática da formação docente e o ensino de cidade}

A formação docente é um tema que preocupa, recorrentemente, os teóricos da educação e os dirigentes do país, nos diferentes níveis, ainda que os diagnósticos, análises e propostas para atender às demandas apresentadas não estejam necessariamente em confluência. Sabe-se dos problemas decorrentes da atuação dos governantes, de um lado, com a implementação de políticas públicas voltadas a essa formação, e, de outro lado, da realidade da prática dessa profissão no Brasil, como as difíceis condições de realização do trabalho docente, as questões da estruturação de plano de carreira e de salário e o baixo prestígio social. No entanto, é possível verificar nas duas últimas décadas um esforço das políticas públicas que tratam dessa temática no sentido de normatizar a formação docente, em nível superior. São referências dessa política as orientações curriculares 
apresentadas pelo Ministério da Educação, na década de 2000, que acarretou mudanças significativas nesses cursos, como as Diretrizes Curriculares Nacionais para a Formação de Professores da Educação Básica, destacando-se a Resolução CNE/CP n. 1/2002, (fundamentada nos Pareceres CNE/CP n ${ }^{\circ}$ 9/2001 e CNE/CP n ${ }^{\circ}$ 27/2001), que institui as DCNs para os cursos de licenciatura; e a Resolução CNE/CES 14/2002 (fundamentada nos Pareceres CNE/CES no 492/2001 e n 1.363/2001), que estabelece as Diretrizes Curriculares para o bacharelado e a licenciatura em Geografia.

Para efeito da pesquisa, interessam diretamente as orientações referentes aos modos de organizar os Estágios Supervisionados, buscando obedecer ao princípio de integração teoria e prática, conforme grande parte dos atuais Projetos Pedagógicos de Cursos (PPCs) das Licenciaturas em Geografia no Brasil. Ainda que se saiba que os currículos prescritos não são os mesmos que os praticados, de todo modo essas políticas legitimam os investimentos nessa formação no sentido de qualificar mais os processos formativos para atender às demandas e grandes desafios da prática. Como resultado dessas políticas, ainda sem análises mais sistemáticas quanto aos seus desdobramentos efetivos na formação docente, é possível verificar mudanças visíveis na maior parte dos Projetos de Curso na área de Geografia, nas diferentes regiões do país, no que diz respeito ao funcionamento da atividade de estágio curricular. Esse estágio tem sido, a partir dessas diretrizes (e de outras posteriores), realizado por meio de mais de uma disciplina, predominantemente 3 a 4 disciplinas obrigatórias, distribuídas ao longo da segunda metade dos cursos (a partir do quinto período nas matrizes curriculares), totalizando, na maior parte dos cursos, 400 horas, entre aulas teórico/práticas e atividades mais efetivas nas escolas de educação básica.

Nesse contexto, o Estágio Supervisionado desempenha ou pode desempenhar um papel muito relevante nos processos formativos, na medida em que se constitui um momento (ou momentos) peculiar de reflexão e de síntese de elementos teóricopráticos da profissão, podendo-se articular de modo explícito as teorias da Geografia e as teorias pedagógico-didáticas. O Estágio pode constituir-se em momento de reflexão e de experiência inicial do papel do professor de Geografia na formação dos alunos, da escola básica, ou seja, na formação para a vida cidadã. Essa reflexão pode estar focada na Geografia e no papel social que ela tem no processo de escolarização, e na função mediadora que o professor desempenha nessa escolarização, contribuindo para que, com a ajuda da Geografia e do estudo da espacialidade dos fenômenos, em suas diferentes escalas e tipos de manifestações, os alunos se desenvolvam como cidadãos capazes de compreender mais ampla e criticamente o mundo em que vivem.

Esse entendimento das demandas do ensino de Geografia na escola básica já está delineado em outros textos (CAVALCANTI, 2008, 2013, entre outros). As preocupações com a formação inicial do professor de Geografia, tendo em vista as demandas de sua prática docente futura, dirigem-se, assim, para o investimento na formação teóricoconceitual do professor para que ele seja capaz de exercer com qualidade seu papel de mediador nos processos cognitivos dos seus alunos, tendo em vista sua formação cidadã. Nesse sentido, algumas questões são pertinentes, como: o que é esse papel mediador do professor? Como se configura a mediação na atividade docente? Fundamentando-se na 
linha dialética, como pode ser sua formação para que ele exerça esse papel? Os cursos de formação de professores de Geografia têm tido a preocupação com a demanda do ensino de formar para a vida urbana cotidiana e para a cidadania? O Estágio Supervisionado, em especial na etapa de desenvolvimento de projetos de intervenção didática na escola, poderia se constituir em um momento especial da formação para a construção de propostas de trabalho docente voltadas à formação com qualidade, no âmbito do ensino de Geografia?

Articulando essa problemática mais geral da formação docente em Geografia com os propósitos do ensino de cidade, pode-se seguir com os questionamentos: como os jovens que estão em processo de formação inicial, para a profissão de professor de Geografia, constroem um pensamento teórico-conceitual sobre cidade e vida urbana capazes de fundamentar suas escolhas na formulação de projetos de intervenção didática, visando à formação cidadã? Por que isso é importante? Que dilemas esses jovens vão encontrando ao longo de sua formação inicial para a constituição de seu papel social/ profissional entre um mundo que vivenciam - predominantemente individualista, utilitarista, imagético, midiático e pragmático - e a formação humana cidadã (que é o material de sua profissão) - que pressupõe um projeto de humanidade e uma capacidade de articulação escalar, entre os fenômenos que ocorrem no local e suas determinações em outras escalas, como a global? Quais os conceitos geográficos mais importantes para compreender as cidades latino-americanas no contexto contemporâneo? Como esses conceitos podem ser sistematizados em uma rede de significados como orientações para seu ensino?

Nesse entendimento, o Estágio Supervisionado se constitui em momento de lidar proximamente com a realidade de sua atividade profissional - observar e coletar dados para diagnósticos de escolas, estabelecer contato com os profissionais da educação (coordenadores, professores e funcionários da escola), observar e contribuir com as aulas de Geografia que são realizadas comumente em escolas, preferencialmente públicas, selecionadas para o estágio. No percurso formativo, portanto, o estágio curricular é relevante tanto por permitir experimentar modos de organizar seu material da profissão (livros didáticos, recursos digitais, textos acadêmicos, textos didáticos autorais, planos de aula, dinâmicas e metodologias de aula), quanto por propiciar momentos de problematização, de reflexão e da experimentação de docência, considerando as suas condições de realizar essa experiência. É momento, pois, de se questionar sobre propósitos da formação geográfica dos alunos, podendo-se contemplar neles a formação para a vida cotidiana cidadã.

Nessa linha de trabalho, a cidade é considerada um dos conceitos geográficos de relevância, pois é lugar da vida cotidiana da maioria da população e também é onde se produz o modo de vida dominante na sociedade contemporânea. O tema da cidade, no ensino de Geografia, contribui para a compreensão da espacialidade contemporânea, para a prática cidadã, dando relevo à sua dimensão territorial, a referência à vida coletiva, e para trabalhar concretamente com conceitos geográficos elementares, como os de paisagem, lugar e território. $\mathrm{O}$ trabalho docente, nessa temática, consiste em fazer a mediação dos alunos com os conteúdos geográficos referentes, buscando propiciar 
encontros/confrontos da vida imediata e cotidiana dos alunos com elementos mais amplos da realidade, por meio dos conceitos científicos, enquanto generalização da experiência. $\mathrm{O}$ ensino de cidade salienta as percepções e vivências cotidianas, e contribui com elementos teóricos para refletir sobre elas, compreendendo esse espaço, para além de sua forma física, como materialização de modos de vida.

Essa abordagem contribui para desenvolver habilidades dos alunos necessárias ao exercício cotidiano de apropriação dos espaços, ao acesso aos seus espaços públicos, que são práticas fundamentais para o usufruto pleno do direito à cidade. Importa, assim, discutir os espaços vividos na cidade, considerando, no entanto, que eles são uma construção constante, dinâmica, na qual interfere a experiência, os deslocamentos cotidianos, o contexto familiar e social, mas também suas aprendizagens, seus conceitos, as referências espaciais aprendidas. Analisar a dinâmica da produção do espaço urbano nesse ponto de vista permite entender melhor a cidade, que, segundo Lefebvre (1991), tem origem histórica na festa, no encontro de pessoas, mas que, no modo de vida atual, transformou-se em mercadoria para ser consumida na lógica econômica. $\mathrm{Na}$ cidade atual domina, assim, a racionalidade capitalista, no entanto a realidade é dinâmica e não se reduz à lógica racional e formal, a modelos predeterminados, e efetivamente, na sua dinâmica, as contra-racionalidades são percebidas (SANTOS,1996); nessa dinâmica, há uma dialética entre o corpo e a globalização, entre as realidades objetivas e as subjetividades (HARVEY, 2004), voltando-se ao devir, a realidade está aberta ao inesperado, ao improvável (pela lógica formal).

Reforça-se, nessa análise, a relação (dialética, interdependente) entre cidade e cidadania, da qual resultará em diferentes possibilidades de desdobramentos do real. $\mathrm{Na}$ atualidade, diversos estudos relacionam a ideia de cidadania com a sociedade moderna, vinculada à perspectiva de participação política do indivíduo em práticas eleitorais. A concepção de cidadania que norteia este estudo, no entanto, é mais ampla, abrange o plano da consciência política, das condições sociais de sobrevivência, do respeito à diversidade cultural, dos processos de aquisição do saber etc. Nessa perspectiva, a cidadania está ligada à participação da vida coletiva incluindo reivindicações de inclusão social, de respeito à diversidade e de direitos mais abrangentes para melhores condições de vida e de sobrevivência. Relaciona-se com o direito a ter direitos, que cria direitos, no cotidiano, na prática da vida coletiva e pública, destacando-se sua dimensão territorial (direito ao usufruto da cidade).

A preocupação com a cidadania liga essa problemática às práticas escolares, particularmente ao ensino de Geografia, pelo qual se pode trabalhar conteúdos referentes à cidade, propiciando instrumentos relevantes ao aluno para que ele possa compreendêla em sua complexidade, a partir de suas próprias experiências com esse espaço, tendo como referência a vida coletiva. Nesta proposta, são importantes os modos como os jovens percebem os lugares/locais da cidade, como têm se relacionado no cotidiano com eles, como em suas ações rotineiras e cotidianas têm se apropriado de seus lugares e produzido territórios.

A pesquisa com jovens tem revelado que eles atuam com referenciais construídos, em diferentes oportunidades de aprendizagem sobre seu lugar de vida cotidiana, mas 
também constroem conhecimentos espaciais (e outros) ao lidarem com diferentes lugares do mundo. Os conteúdos da Geografia escolar servem como referenciais desses jovens, mas é preciso que eles formem conceitos sólidos e amplos a respeito das temáticas ligadas à sua vida. Na escola, circulam conhecimentos com a meta de se ampliarem referências mais imediatas. Como alertam Charlot (2009) e Young (2011), a cidade estudada/ensinada na escola não é a mesma que os jovens vivenciam empiricamente, pois se trata de uma leitura, de uma possibilidade de leitura dessa cidade. Na verdade, é a mesma cidade, mas vista e lida sob outra perspectiva, a da ciência/matéria de referência: a Geografia, sendo assim mais ampla e abstratamente apreendida.

Para o professor de Geografia, é importante, sobretudo, compreender as práticas espaciais dos jovens escolares, pois elas são produtoras de geografia. É também de grande valia conhecer suas próprias experiências geográficas, seus conhecimentos empíricos nessa área, suas demandas, para problematizá-los, propiciando assim motivações para o estudo e para o avanço dos seus próprios saberes.

Tal compreensão justifica, portanto, a necessidade de investigar estratégias de formação dos professores que tenham como foco a relação entre o cidadão jovem escolar, em sua prática cotidiana, o espaço urbano/cidade e o ensino de Geografia. Trata-se, pois, de apostar na formação inicial do professor de Geografia buscando, em momentos peculiares dessa formação como o estágio supervisionado, compreender seus conceitos sobre "cidade e vida urbana" e propiciar momentos de reflexão e vivência, com base nesses conceitos, sobre modos de trabalhar no ensino, visando ao desenvolvimento do pensamento teórico-conceitual dos seus alunos.

Com essa problemática, definiu-se o objetivo geral da investigação: analisar as potencialidades da mediação didática para o desenvolvimento do pensamento teórico-conceitual sobre cidade e vida urbana, em experiências formativas de alunos estagiários do Curso de Licenciatura em Geografia da Universidade Federal de Goiás - UFG (Goiânia). Para alcançar esse objetivo, foram orientadores do trabalho os seguintes objetivos específicos: - Verificar, nos princípios gerais e na matriz curricular do Projeto Pedagógico do curso de Licenciatura em Geografia da UFG, as possibilidades explicitadas de tratamento dos conteúdos "cidade e vida urbana" no âmbito do processo de formação; - Caracterizar as concepções de cidade e vida urbana de alunos estagiários do curso de formação de professores de Geografia da UFG; - Identificar, junto a alunos estagiários do curso de Geografia da UFG, momentos e elementos do desenvolvimento do pensamento teórico-conceitual sobre cidade e vida urbana explorados ao longo do curso de formação; - Analisar as relações que alunos estagiários estabelecem entre o que aprendem no curso de formação de professores de Geografia sobre cidade e vida urbana e o que vivenciam em seu cotidiano; - Acompanhar, orientar e avaliar experiências de intervenção didática no âmbito do Estágio supervisionado do Curso de Geografia da UFG, com a adoção de propostas de mediação didática para o estudo de cidade e vida urbana; - Ampliar a discussão de elementos de proposta de formação para professores de Geografia, incorporando as possibilidades de desenvolvimento do pensamento teórico-conceitual, identificadas ao longo da pesquisa; - Subsidiar os debates e a produção acadêmica - definida em projetos de investigação integrados - com grupos 
de pesquisadores nacionais e internacionais da área de Didática e Ensino da Geografia, sobre a temática do ensino de cidade; - Investigar junto a pesquisadores e grupos de investigação do Brasil (São Paulo-USP) e América Latina (Argentina, Colômbia e Chile) referências teórico-conceituais para a compreensão de cidade e vida urbana no contexto latino-americano e suas sistematizações para o ensino dessa temática. Esse último objetivo específico norteou especificamente uma etapa da pesquisa, a qual será melhor tratada na sequência do texto.

\section{Caminhos metodológicos no ensino de cidade}

$\mathrm{Na}$ minha trajetória de pesquisa, tenho buscado entender como se pode orientar experiências de professores em formação inicial que contribuam para o desenvolvimento de seu pensamento teórico-conceitual. Em projetos anteriores, pude encaminhar atividades com alunos em formação focadas na abordagem de conteúdos geográficos com a temática urbana de modo articulado à vida cotidiana dos alunos da escola básica, com preocupação mais explícita de participação cidadã. Foi possível ao final sistematizar uma orientação para intervenções na escola, com esse propósito, conforme quadro a seguir:

Quadro I. Percurso didático para ensinar Geografia da cidade - Goiânia, 2014

\section{Percurso didático para ensinar Geografia na escola para a participação cidadã}

1. Escolha da Unidade Temática: partir de temas já previstos no currículo escolar;

2. Problematização: problematizar esse tema, relacionando-o com a realidade local vivenciada mais diretamente pelos alunos;

3. Apresentação de material informativo/documentos: apresentar aos alunos documentos/ informações sobre o planejamento urbano do município (se houver) ou dados de pesquisa sobre o tema escolhido;

4. Sistematização de conhecimentos geográficos relacionados ao tema: com base no planejamento de ensino e no livro didático já adotado, preparar material didático ou aula(s) expositiva(s) com a sistematização/explicação de conhecimentos básicos que estão relacionados ao tema e ao nível de ensino trabalhado;

5. Definição de Agenda de demandas: solicitar dos alunos a confecção de uma agenda de demandas para a cidade (ou bairro), a partir do material e das discussões anteriores;

6. Envolvimento da escola: se possível, envolver, nessa atividade, outros sujeitos da escola, outros professores e/ou turmas de alunos e coordenadores/diretores da escola;

7. Elaboração de documento aos gestores: elaborar uma carta aos governantes (ou à Câmara de Vereadores) contendo a agenda elaborada e a fundamentação dessa agenda;

8. Contato com gestores: encaminhar carta (ou entregá-la pessoalmente) a algum representante do gestor da cidade, promovendo discussão os responsáveis, quando possível;

9. Discussão dos resultados: discutir com os alunos os resultados da experiência para sua aprendizagem.

Fonte: Elaboração da autora, tendo como base pesquisas realizadas e relatórios de pesquisa (CAVALCANTI e SOUZA, 2014; SILVA, 2013; ALMEIDA, 2014). 
Como é possível perceber, há uma mediação didática que está pressuposta nesse tipo de intervenção, nas experiências já realizadas com esse encaminhamento, que foi elaborada em coerência com as orientações metodológicas de fundamentação dialética (sobretudo com base em Vygostsky, 1993, 2000), exposta em Cavalcanti (2014), e sintetizada no Quadro II.

Quadro II. Mediação Didática para o ensino de Metrópole/Goiânia - 2014

\begin{tabular}{|c|c|c|}
\hline \multicolumn{3}{|c|}{ Mediação Didática } \\
\hline Problematizar & Sistematizar & Sintetizar \\
\hline \multicolumn{3}{|c|}{ Percurso Didatico para o estudo da metrópole (I) } \\
\hline $\begin{array}{l}\text { Identificando os grupos, seus } \\
\text { problemas cotidianos e seus } \\
\text { lugares }\end{array}$ & $\begin{array}{l}\text { Compreendendo os territórios; } \\
\text { Descobrindo os espaços públicos e } \\
\text { discutindo a cidadania; } \\
\text { Explorando conceitos }\end{array}$ & Narrando espacialidades \\
\hline \multicolumn{3}{|c|}{ Possibilidades temáticas para o estudo da metrópole } \\
\hline $\begin{array}{l}\text { Interrogando práticas } \\
\text { de grupos em paisagens } \\
\text { urbanas: } \\
\text { As práticas espaciais na } \\
\text { cidade, particularmente } \\
\text { de jovens escolares (suas } \\
\text { paisagens, as identidades } \\
\text { impressas, seus lugares, suas } \\
\text { marcas na cidade); } \\
\text { Jovens como agentes de } \\
\text { espacialidades: quem são } \\
\text { os alunos? Que lugares são } \\
\text { referências para eles? Com } \\
\text { que lugares se identificam? } \\
\text { Quais são seus espaços de } \\
\text { socialização? } \\
\text { Definindo problemas } \\
\text { urbanos cotidianos: } \\
\text { Mobilidade/acessibilidade, } \\
\text { transporte/trânsito, } \\
\text { habilitação, segurança/ } \\
\text { violência, educação, } \\
\text { lugares de lazer (parques, } \\
\text { bosques e praças) e cultura, } \\
\text { qualidade de vida e qualidade } \\
\text { ambiental, saneamento, } \\
\text { abastecimento de água, } \\
\text { oportunidade de emprego, } \\
\text { desemprego, exclusão social/ } \\
\text { segregação/discriminação, } \\
\text { existência de desabrigados, } \\
\text { tráfico de drogas, saúde } \\
\text { pública. }\end{array}$ & $\begin{array}{l}\text { Sistematizando elementos do } \\
\text { conceito discutindo conceitos } \\
\text { mais específicos relacionados, no } \\
\text { tratamento de temas: } \\
\text { Criação e formação da metrópole } \\
\text { (escolha do local, sítio, marcos } \\
\text { iniciais); } \\
\text { Centros originais deteriorados / } \\
\text { gentrificação, centralidades; } \\
\text { Ambiente urbano (elementos do } \\
\text { clima urbano, sistema de saneamento } \\
\text { e tratamento de água, nível e tipos } \\
\text { de poluição, presença e qualidade do } \\
\text { sistema de drenagem, preservação de } \\
\text { áreas verdes, solos permeáveis); } \\
\text { Bacias e sub-bacias hidrográficas; } \\
\text { Processos de expansão acentuada e } \\
\text { descontinua de malhas urbanas; } \\
\text { Crescimento de periferia pobre e de } \\
\text { condomínios fechados; } \\
\text { Processo de conturbação; } \\
\text { Valorização do solo urbano e } \\
\text { segregação sócio-espacial; } \\
\text { Relação entre cidades e a atratividade } \\
\text { das metrópoles, rede urbano-regional; } \\
\text { Espaços públicos (de uso coletivo) e } \\
\text { espaços privados; } \\
\text { Agentes da dinâmica urbana e a } \\
\text { produção do espaço; } \\
\text { A políticia urbana e a gentes } \\
\text { econômicos; } \\
\text { Movimentos sociais urbanos, } \\
\text { diferentes grupos sociais e suas } \\
\text { territorializações. }\end{array}$ & $\begin{array}{l}\text { Produzindo Narrativas: } \\
\text { Deslocamentos diários e as } \\
\text { práticas urbanas; } \\
\text { A metrópole vivida e a } \\
\text { metrópole aprendida. } \\
\text { Lugares de práticas } \\
\text { cotidianas: } \\
\text { Acessibilidade, publicidade } \\
\text { dos lugares; } \\
\text { Região Metropolitana: } \\
\text { elementos de sua } \\
\text { identificação; } \\
\text { Reflexão sobre problemas } \\
\text { urbanos. } \\
\text { Produzindo desenhos/mapas } \\
\text { mentais: } \\
\text { Desenhos da cidade em } \\
\text { períodos históricos diferentes } \\
\text { - a cidade percebida/ } \\
\text { imaginada no tempo; } \\
\text { Trajetórias individuais } \\
\text { cotidianas na metrópole; } \\
\text { Marcas da metrópole: } \\
\text { mobiliários urbanos, } \\
\text { equipamentos, vias e } \\
\text { referências do espaço vivido; } \\
\text { Paisagens vividas, concebidas } \\
\text { e imaginadas. }\end{array}$ \\
\hline
\end{tabular}

Fonte: Elaboração da autora (CAVALCANTI, 2014) 
Assim, a investigação em andamento busca ampliar as experiências formativas para a profissionalização do professor de Geografia, em cursos de graduação, tendo em vista o desenvolvimento de propostas de trabalho docente, em Estágios Supervisionados, voltados para a formação dos alunos sobre cidade e vida urbana, orientando-se por essa metodologia. A pesquisa tem como base empírica o curso de Geografia da UFG e escolas de ensino básico de diferentes municípios do Estado de Goiás.

Adota-se, como já foi mencionado, a perspectiva qualitativa de pesquisa e a modalidade de Pesquisa-ação, na medida em que sua problemática surgiu da própria prática do pesquisador e a partir dela define-se um plano de ação, buscando avaliar os resultados tendo como referência a problemática focada (Thiollent, 1996). Nesse sentido, os procedimentos metodológicos definidos são: levantamento e análise bibliográfica; análise documental do projeto pedagógico do curso e de planos de ensino; entrevistas com especialistas em didática da Geografia, de Universidades latino-americanas; aplicação de questionários; realização de grupos de discussão; desenvolvimento de projetos de intervenção pedagógica; avaliação da experiência por alunos estagiários e análise dos dados para elaboração do relatório final.

Espera-se, com o desenvolvimento da pesquisa, fundamentar concepções para elaboração de propostas de formação do professor de Geografia que o habilite a trabalhar com os temas da cidade e da vida urbana de modo a formar cidadãos no âmbito da Educação Básica. Com base nessa orientação metodológica, as etapas da pesquisa são:

Quadro III. Etapas da Pesquisa - 2016

\begin{tabular}{|c|c|}
\hline Pesquisa Bibliográfica & Pesquisa Empírica \\
\hline $\begin{array}{l}\text { - Levantamento bibliográfico sobre as temáticas } \\
\text { mais recorrentes na Geografia Urbana brasileira e da } \\
\text { América Latina; } \\
\text { - Ampliação e sistematização dos dados coletados em } \\
\text { Anais e periódicos, na temática da Juventude e das } \\
\text { práticas espaciais cotidianas, como fundamento para } \\
\text { interpretação das percepções de jovens sobre a cidade; } \\
\text { - Ampliação de levantamento e estudo bibliográfico de } \\
\text { obras de autores que focam na temática da formação } \\
\text { docente, na mediação didática e no papel dos estágios } \\
\text { nessa formação, tendo como base a linha teórica de } \\
\text { Vygotsky. }\end{array}$ & $\begin{array}{l}\text { - Coleta de informações junto a especialistas da } \\
\text { Didática da Geografia na América Latina, sobre } \\
\text { o conceito de cidade, fontes de referência para } \\
\text { o tratamento desse conceito e seus caminhos } \\
\text { metodológicos; } \\
\text { - Coleta de dados com alunos estagiários do } \\
\text { curso de Licenciatura de Geografia na UFG, } \\
\text { nos seguintes momentos: questionário e grupo } \\
\text { de discussão com alunos do período inicial de } \\
\text { estágio; formação de grupos de alunos para a } \\
\text { experiência com a metodologia sugerida para } \\
\text { a mediação didática; o desenvolvimento de } \\
\text { atividades de orientação didática; produção de } \\
\text { narrativas dos alunos estagiários, ao final do } \\
\text { processo, sobre a experiência realizada. }\end{array}$ \\
\hline
\end{tabular}

Fonte: elaboração da autora

\section{Considerações preliminares sobre os resultados produzidos}

Com o intuito de ampliar a compreensão da temática referente ao urbano e assim subsidiar as orientações sobre sua abordagem no ensino de Geografia, em momentos de formação docente, buscando alcançar o objetivo geral da pesquisa, foi realizada 
entrevista estruturada com especialistas da Didática dessa disciplina em países da América Latina: Argentina, Chile, Colômbia e Brasil. Nesse contato com os especialistas, no segundo semestre de $2016^{1}$, foi possível levantar tópicos, fontes de estudo e formas de abordagem do tema que serão tomados como referência para fundamentar o trabalho com estagiários de Geografia, a ser realizado ao longo de 2017 e 2018, conforme previsto na metodologia. A intenção foi analisar os tópicos e abordagens, bem como as indicações de autores para o trabalho com a temática, para subsidiar a reformulação (confirmação, revisão, ampliação) do Quadro II, apresentado anteriormente, no sentido de tomá-lo como orientador para a definição das intervenções dos grupos de estagiários nas escolas.

Os especialistas consultados, em um total de 30 professores, estão assim distribuídos: Argentina, 8; Chile, 8; Colômbia, 5; Brasil, 9. A grande parte deles está envolvida com a formação docente em Geografia, tendo formação básica na área ou em áreas afins, e a maioria deles, 70\%, tem mestrado ou doutorado em Geografia ou em áreas afins. Alguns dados produzidos com base na sua contribuição serão apresentados a seguir.

Uma pergunta inicial aos entrevistados diz respeito aos conceitos que consideram fundamentais para trabalhar a cidade no ensino de Geografia, assim formulada: "cuáles serían los conceptos geográficos más importantes para comprender y explicar los principales problemas socio territoriales de las ciudades latinoamericanas en el contexto contemporáneo?". Nas respostas a essa pergunta foi possível identificar 86 conceitos, divididos em três grupos ${ }^{2}$.

$\mathbf{1}^{\mathbf{0}}$. Conceitos mais gerais - Nesse grupo foram considerados os conceitos mais gerais, geográficos ou não, identificando-se 29 conceitos ou grupos de conceitos, dos quais são destacados a seguir os que foram citados quatro vezes ou mais.

Quadro IV. Conceitos mais gerais citados por especialistas na área - Goiânia, 2016

\begin{tabular}{|l|c|}
\hline Conceitos & $\begin{array}{c}\text { No de } \\
\text { citações }\end{array}$ \\
\hline $\begin{array}{l}\text { Território/território usado/poder/ territorialidade/Territorialização-esterritorialização- } \\
\text { reterritorialização }\end{array}$ & 11 \\
\hline Lugar/localização/conjunto de lugares/ sítio urbano/localização e situação & 8 \\
\hline Interação espacial/Redes/ articulação/ red y entramado urbano & 7 \\
\hline Paisagem/paisagem urbana & 6 \\
\hline Espacio geográfico es un producto social/produção do espaço/espaço geográfico & 6 \\
\hline Região & 4 \\
\hline $\begin{array}{l}\text { Multiescalaridade/ Multiescalaridad temporoespacial/ Global e local, universal e } \\
\text { singular/Escala de analise/escala }\end{array}$ & 4 \\
\hline Globalização/capitalismo e globalização & 4 \\
\hline Espaço urbano/urbano & 4 \\
\hline
\end{tabular}

Fonte: elaboração da autora

1. Essa etapa da pesquisa foi realizada durante um estágio pós-doutoral realizado na Universidade de Buenos Aires, Argentina, sob a supervisão da professora Maria Victoria Fernandez Caso.

2. Procurando manter maior fidedignidade das informações, as citações estão grafadas conforme foram escritas, ora em português, ora em espanhol. 
$\mathbf{2}^{\mathbf{0}}$. Conceitos urbanos mais genéricos. Nesse grupo estão reunidos 24 conceitos ou grupos de conceitos, os mais gerais que, no meu entendimento, têm sido atribuídos aos estudos geográficos do urbano. Desses, estão apresentados no quadro seguinte aqueles que se destacaram porque foram citados quatro vezes ou mais.

Quadro V. Conceitos urbanos genéricos citados por especialistas - Goiânia, 2016

\begin{tabular}{|l|c|}
\hline Conceitos & No. de citações \\
\hline $\begin{array}{l}\text { Segregação/segregação sócio-territorial/exclusão sócio-territorial/ Segmentación } \\
\text { y segregación urbana/ Exclusión, Inclusión y Segregación/ segregación socio- } \\
\text { territorial/ segregación socioespacial/ segregación, exclusión, autoexclusión }\end{array}$ & 12 \\
\hline $\begin{array}{l}\text { Direito à cidade/ uso e apropriação da cidade/ O direito à casa e o habitat/acesso } \\
\text { universal/espaço público y direito à cidade/ O transporte, a cidade e o direito à } \\
\text { mobilidade }\end{array}$ & 10 \\
\hline $\begin{array}{l}\text { Gentrificação/gentrificação e despejo/bairros fechados e gentrificação/ gentrificação/ } \\
\text { gentrificação e deslocamento/ Renovação }\end{array}$ & 9 \\
\hline $\begin{array}{l}\text { Metrópole/megalópole/áreas metropolitanas reestructuración territorial y } \\
\text { metropolización/ área metropolitana, megalópoles, metápolis }\end{array}$ & 7 \\
\hline $\begin{array}{l}\text { Renda da Terra/Valorização social e capitalista do espaço urbano/valorização do solo/ } \\
\text { Valor de uso y Valor de cambio del suelo/globalización y modelo de valorización } \\
\text { financiera en la ciudad contemporánea }\end{array}$ & 5 \\
\hline $\begin{array}{l}\text { Fragmentação/Fragmentación, heterogeneidad y desigualdades urbanas/ } \\
\text { fragmentación/espaços fragmentados }\end{array}$ & 5 \\
\hline $\begin{array}{l}\text { Desigualdades sociais e urbanas/desigualdade sócio-territorial/desigualdade } \\
\text { social/desigualdade }\end{array}$ & 5 \\
\hline Espaço público-privado/ Espacios públicos e infraestructuras urbanas/espaço público & 4 \\
\hline Urbanização/processo de urbanização & 4 \\
\hline $\begin{array}{l}\text { Estado e políticas urbanas/políticas estatais e planificação urbana/políticas } \\
\text { públicas/políticas }\end{array}$ & 4 \\
\hline Suburbanização & 4 \\
\hline
\end{tabular}

Fonte: elaboração da autora

$3^{\text {0 }}$ Conceitos mais específicos. Nesse grupo estão os 33 conceitos ou grupo de conceitos considerados mais específicos, que tratam de fenômenos como guetização, criminalização, bairro e comunidade, ou que tem uma formulação muito peculiar, que não permite agrupamentos, sem correr o risco de equívoco de entendimento, como: "construção social da cidade", "Modelos sociales de acumulación y conformación histórica de la ciudad", "modelos de ciudad de los Estados Unidos, Europa y América Latina”. A seguir, estão destacados os que foram citados quatro vezes ou mais.

Quadro VI. Conceitos mais específicos citados por especialistas - Goiânia, 2016

\begin{tabular}{|l|c|}
\hline Conceitos & No. de citações \\
\hline $\begin{array}{l}\text { Imaginarios urbanos/ prácticas -representaciones sociales e imaginários/ imagen e } \\
\text { imaginario urbano/ semiótica urbana }\end{array}$ & 4 \\
\hline Uso do solo/mercantilização do solo urbano & 4 \\
\hline
\end{tabular}

Fonte: elaboração da autora 
A partir da leitura desses dados, é possível fazer diferentes leituras dessas indicações para o tratamento didático do tema da cidade. Uma maneira considerada eficaz de fazê-lo é buscar sua inserção no Quadro II, no momento da sistematização de conceitos para, estruturando-os como um "plano de fundo", nortear a abordagem dos demais conceitos, conforme formulação destacada em negrito. Assim, pode-se elaborar para o $1^{\circ}$ grupo a seguinte figura representativa:

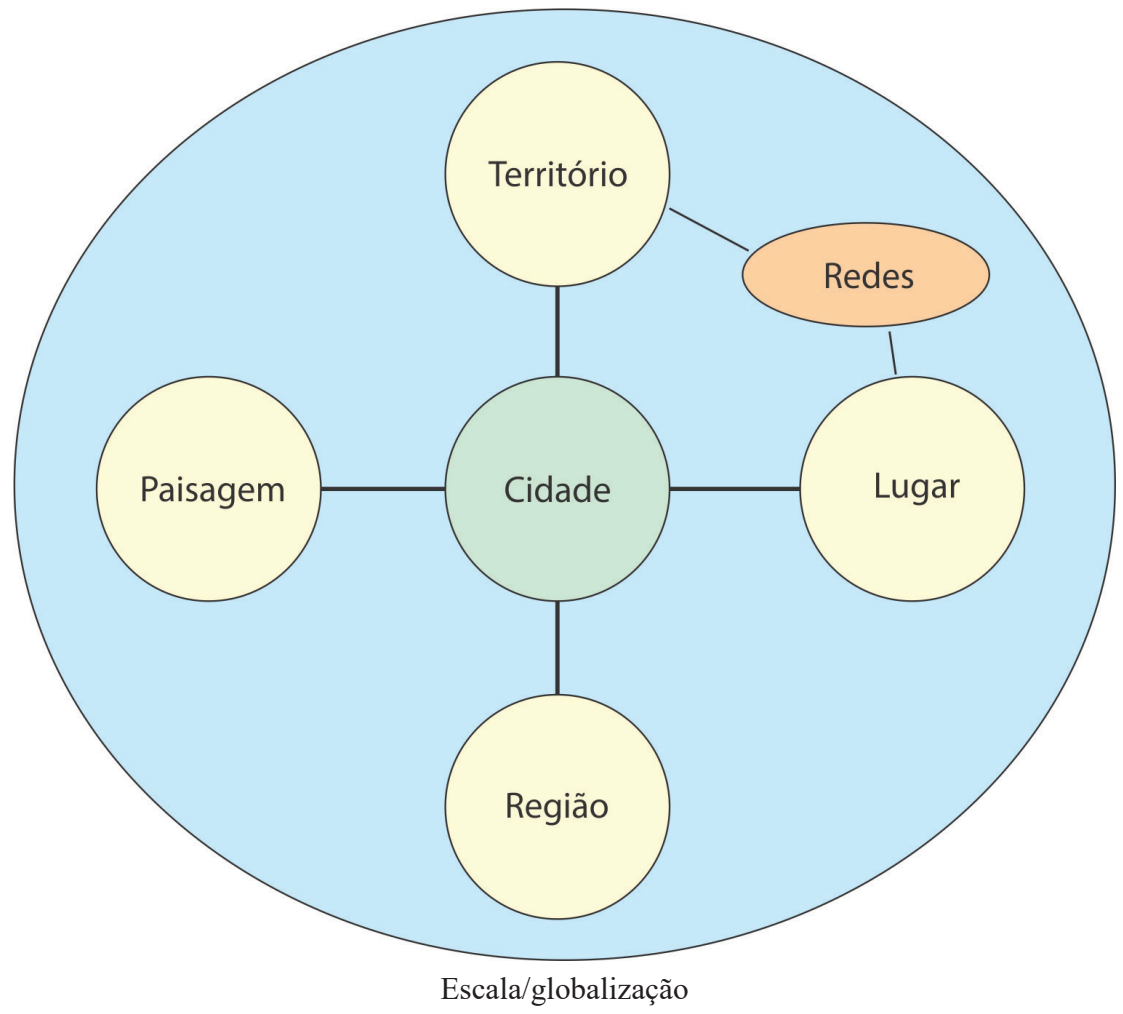

Tomando como base essa sistematização indicada pelos especialistas, e que confirma e amplia minha própria formulação já apresentada em outros momentos (cf., por exemplo, CAVALCANTI, 2013, 2014), essa formulação poderá ser norteadora no trabalho para a formação de conceitos propriamente urbanos, destacados no $2^{\circ}$. e $3^{\circ}$. grupos, A confrontação entre os temas arrolados no quadro da mediação didática para o ensino de metrópole (Quadro II) e o referente aos temas indicados pelos especialistas permite uma análise das suas potencialidades para abordar o tema por meio de um sistema conceitual relevante, conforme pode ser visualizado no quadro a seguir: 
Quadro VII. Quadro comparativo de dados do Quadro II e dos Quadros V e VI - Goiânia, 2016

Quadro II - parte do quadro que trata do momento da
sistematização discutindo conceitos mais específicos
relacionados, no tratamento de temas):

Criação e formação da metrópole (escolha do local, sítio, marcos iniciais);

Centros originais deteriorados/gentrificação, centralidades;

Ambiente urbano (elementos do clima urbano, sistema de saneamento e tratamento de água, nível e tipos de poluição, presença e qualidade do sistema de drenagem, preservação de áreas verdes, solos permeáveis);

Bacias e sub-bacias hidrográficas;

Processos de expansão acentuada e descontinua de malhas urbanas;

Crescimento de periferia pobre e de condomínios fechados;

Processo de conurbação;

Valorização do solo urbano e segregação sócio-espacial;

Relação entre cidades e a atratividade das metrópoles, rede urbano-regional;

Espaços públicos (de uso coletivo) e espaços privados;

Agentes da dinâmica urbana e a produção do espaço;

A políticia urbana e agentes econômicos;

Movimentos sociais urbanos, diferentes grupos sociais e suas territorializações.
Quadro V e VI - Conceitos relevantes apontados pelos especialistas apontados por especialistas na área:

Direito à cidade

Segregação/gentrificação/fragmentação

Valorização/uso do solo

Urbanização/metropolização/

suburbanização

Imaginários urbanos, Politicas estatais e planificação urbana

Nessa comparação, à primeira vista verifica-se muitas coincidências (em negrito) entre o que já havia sido definido como sistema de conceitos relevantes para o estudo da cidade (Quadro II), reforçando-os, dessa maneira como adequados como meta para esse ensino; além disso, é possível ainda apontar alguns conceitos (destacados com um contorno nas palavras, na primeira coluna) que embora não tenham sido citados pelos especialistas, podem permanecer como apostas no trabalho a ser realizados nos estágios em prol da formação cidadã.

Seguindo com a análise dos dados coletados, como fonte para o estudo das temáticas urbanas, que se pode tomar como referência para o significado desses diferentes conceitos, foram citados 95 teóricos (relacionado ou não a alguma obra específica). Entre eles, estão elencados a seguir aqueles que foram citados por mais de 3 especialistas, reforçando assim a relevância que eles têm como fontes da Geografia acadêmica para a Geografia escolar, quando se trata de ensinar temas sobre cidade e vida urbana: 
Quadro VIII. Autores citados como contribuição para o estudo de urbana por especialistas. Goiânia, 2016

\begin{tabular}{|l|c|}
\hline Autores citados & No. de citações \\
\hline Milton Santos & 17 \\
\hline David Harvey & 13 \\
\hline Henri Lefebvre & 11 \\
\hline Doreen Massey & 06 \\
\hline Manoel Castells & 06 \\
\hline Edward Soja & 04 \\
\hline Saskia Sassen & 04 \\
\hline Rogério Haesbaert & 04 \\
\hline Roberto Lobato Correa & 04 \\
\hline Jorge Blanco & 03 \\
\hline Carlos de Mattos & 03 \\
\hline Ana Fani A. Carlos & 03 \\
\hline Raquel Gurevich & 03 \\
\hline Daniel Hiernaux & 03 \\
\hline Jane Jacobs & 03 \\
\hline
\end{tabular}

Fonte: elaboração da autora

Na continuidade do tratamento da contribuição dos especialistas, estão aqueles referentes às referências pedagógicas e aos caminhos metodológicos por eles indicados como relevantes no tratamento dos temas da cidade. Essas indicações e a pesquisa bibliográfica, sobretudo tendo como referência as fontes teóricas indicadas, servirão, por sua vez, de apoio, como já foi dito, ao trabalho com os estagiários no sentido de realizar experiências com o ensino de cidade que contribua para a elaboração de redes de significados para seu ensino, que é um dos objetivos da investigação, e prover, assim, bases teórico-práticas de reflexão sobre a relevância do pensamento teórico-conceitual dos professores de Geografia.

A consulta aos especialistas ajudou a reforçar as convicções sobre contribuições teóricas adequadas ao tratamento de temas referentes ao urbano, com o enfoque nas relações cidade e cidadania, como está sendo destacado no texto. Autores como Milton Santos, David Harvey e Henri Lefebvre foram, pode-se dizer, os mais indicados para esse tratamento, e outros, como Edward Soja e Doreen Massey, apesar de terem menores indicações são relevantes para aprofundar as referências teóricas. Pela leitura das obras desses autores, ou de parte delas, é possível perceber que há inúmeras confluências entre suas ideias: no caminho analítico adotado, o dialético; nos temas e conceitos selecionados para essa análise, nas quais estão contemplados plenamente aqueles que foram destacados pelos próprios especialistas (nos quadros anteriores); nas alternativas sugeridas para a cidade e vida urbana (pode-se exemplificar a explanação de alternativas nos livros seguintes: Espaços de Esperança, David Harvey, 2004; Por uma outra globalização, Milton Santos, 2004 e Direito à cidade, Henri Lefebvre, 1991), que pressupõem a ação cidadã, dependente de fundamentos teóricos que a oriente, o que mune, por sua vez, a ação docente nessa direção: ajudar os alunos, por meio da Geografia escolar, a formar 
referenciais mais seguros e genéricos para analisar a complexidade da espacialidade urbana contemporânea, da qual faz parte como cidadão em seu local de vivência e no mundo como um todo.

\section{Referências}

ALMEIDA Regis R. Planejamento e gestão urbanos e a participação popular: a contribuição da escola e da educação geográfica. 2014. Dissertação de Mestrado. Programa de Pós-Graduação em Geografia - Goiânia/UFG, 2014.

CAVALCANTI, Lana de S. A metrópole em foco no ensino de Geografia: o que/para que/para quem ensinar? PAULA, Flávia M. de A. e outros (orgs.). Ensino de Geografia e Metrópole. Goiânia-GO. Gráfica e Editora América, 2014.

. A Geografia escolar e a cidade. Campinas-SP: Papirus, 2013.

; SOUZA, Vanilton C.. Formação inicial do professores de geografia: desafios às práticas de ensino para atuar na educação cidadã. Relatório de pesquisa, 2013.

CHARLOT, Bernard. O trabalho docente, a análise da actividade e o papel dos sujeitos. Texto da conferência proferida na Faculdade de Psicologia e de Ciências da Educação da Universidade de Lisboa. Sísifo. Revista de Ciências da Educação. (2009) Disponível em: http://sisifo.fpce.ul.pt. Consultado em [agosto/2012]. Acesso em: 10 ago. 2012.

HARVEY, D.. Espaços de Esperança. São Paulo: Edições Loyola, 2004.

LEFEBVRE, Henri. O direito à cidade. São Paulo: Morais, 1991.

SANTOS, M. A natureza do espaço, técnica e tempo, razão e emoção. São Paulo: HUCITEC, 1999.

. Por uma outra globalização: do pensamento único à consciência universal. Rio de Janeiro, Record, 2004.

SILVA, Silvana A. da. A temática da dinâmica intra-urbana de Aparecida de Goiânia para a formação cidadã juvenil. Monografia de Graduação. Curso de Geografia. Universidade Federal de Goiás, 2013.

YOUNG, M. O futuro da educação em uma sociedade do conhecimento: o argumento radical em defesa de um currículo centrado em disciplinas. Revista Brasileira de Educação. Vol. v. 16, no. 48, Rio de Janeiro, set./dez. 2011. Disponível em: http://www. scielo.br/scielo.php?script=sci_arttext\&pid=s1413-24782011000300005\&1. Acesso em: 20 abril 2012.

THIOLlENT, M.. Metodologia da pesquisa-ação. 7. ed. São Paulo: Cortez, 1996.

VYGOTSKY, L.S. Pensamento e linguagem. São Paulo: Martins Fontes, 1993.

. A construção do pensamento e da linguagem. São Paulo: Martins Fontes, 2000. 
Lana de Souza Cavalcanti

Doutora em Geografia Humana pela Universidade de São Paulo, mestre em Educação pela Universidade Federal de Goiás. Atualmente é pesquisadora do $\mathrm{CNPq}(\mathrm{PQ})$ e é professora titular no Instituto de Estudos Socioambientais da Universidade Federal de Goiás, onde atua também no Programa de PósGraduação em Geografia.

Rua 13, no. 36, apto. 901, Cep: 74120-060, Setor Oeste. Goiânia, Goiás Email: 1s.cavalcanti@uol.com.br

Recebido para publicação em dezembro de 2016 Aprovado para publicação em março de 2017 